\title{
Testicular Mixed Embryonal Carcinoma and Yolk Sac Tumor
}

National Cancer Institute

\section{Source}

National Cancer Institute. Testicular Mixed Embryonal Carcinoma and Yolk Sac Tumor.

NCl Thesaurus. Code C8001.

A malignant non-seminomatous germ cell tumor arising from the testis. It is

characterized by a mixture of embryonal carcinoma and yolk sac morphologic elements.

Patients may present with painless or painful testicular swelling. 